\title{
Seroprevalencia de diarrea viral bovina en hatos lecheros del Valle del Mantaro, Región Junín, Perú
}

\author{
Seroprevalence of bovine viral diarrhoea in dairy herds of the Mantaro Valley, \\ Junín Region, Peru
}

\author{
Fernando Arauco Villar ${ }^{1,3}$, Elías Lozano Salazar ${ }^{2}$
}

\section{Resumen}

Se determinó la seroprevalencia de la diarrea viral bovina (DVB) en hatos lecheros de las cuatro provincias que conforman el Valle del Mantaro, Región Junín, Perú, así como la presencia de animales persistentemente infectados, mediante la técnica de ELISA. Se tomaron 425 muestras de sangre de animales de 37 hatos y se aplicó paralelamente una encuesta epizootiológica. La prevalencia muestral de DVB para las cuatro provincias fue $66.3 \%$ y la prevalencia/hato de $64.8 \%$. La provincia de Concepción registró la prevalencia muestral y por hato más altas (75.2 y $75.5 \%$, respectivamente) y Huancayo presentó las más bajas (48.3 y 52.3\%, respectivamente). La prevalencia de animales PI con DVB en las cuatro provincias fue de $5.8 \%$. Los factores de riesgo para la presentación de DVB fueron el sistema intensivo de crianza (OR: 6.545), tipo de hato abierto (OR: 6.33), inseminación artificial (OR: 7.895) y presencia masiva de ratas (OR: 5.714). Existió asociación positiva entre altas prevalencias de DVB con la presencia de vacas repetidoras, abortos y nacimientos anómalos.

Palabras clave: valle del Mantaro; diarrea viral bovina; prevalencia; persistentemente infectado; factores de riesgo

\section{Abstract}

The seroprevalence of bovine viral diarrhoea (DVB) in dairy herds and the presence of persistently infected animals in the four provinces of the Mantaro Valley, Peru were determined using the ELISA technique. A total of 425 blood samples were taken from

\footnotetext{
${ }^{1}$ Facultad de Zootecnia, Universidad Nacional del Centro del Perú, Huancayo, Perú

2 Universidad Norbert Wiener, Lima, Perú

${ }^{3}$ E-Mail: faraucov@gmail.com
}

Recibido: 1 de marzo de 2018

Aceptado para publicación: 15 de septiembre de 2018 
animals of 37 herds and an epizootic survey was applied in parallel. The prevalence of DVB of the four provinces was $66.3 \%$ and the prevalence/herd of $64.8 \%$. The province of Concepción showed the highest sample and herd prevalence (75.2 and 75.5\%, respectively, and Huancayo had the lowest (48.3 and 52.3\%, respectively). The prevalence of PI animals with DVB in the four provinces was $5.8 \%$. Risk factors for the presentation of DVB were the intensive breeding system (OR: 6.545), open herd type (OR: 6.33), use of artificial insemination (OR: 7.895) and massive presence of rats (OR: 5.714). There was a positive association between high prevalence of DVB with the presence of repeat breeder cows, abortions and anomalous births.

Key words: Mantaro valley; bovine viral diarrhoea; prevalence; persistently infected; risk factors

\section{INTRODUCCIÓN}

El creciente desarrollo de la ganadería lechera en la región Junín, Perú viene incentivando el desarrollo de la investigación sobre su problemática sanitaria, particularmente sobre algunas enfermedades causantes de abortos como la Diarrea Viral Bovina (DVB), enfermedad de gran repercusión económica (Grooms, 2004), debido a los problemas reproductivos (abortos, infertilidad), menor desarrollo corporal y de producción de leche, así como muerte de animales jóvenes (Valle et al., 2005).

El virus de la DVB (VDVB) es miembro del género Pestivirus, de genoma ARN, relacionado antigénicamente con el virus de la peste porcina clásica (vPPC) y con el virus de la Enfermedad de la Frontera (VEF), que afectan al porcino y al ovino respectivamente (Paton, 1995; Vega et al, 2000). Aunque el VDVB es uno de los agentes infecciosos más estudiados en el ganado bovino, es probablemente uno de los menos comprendidos, debido principalmente porque pertenece a un grupo de virus que afectan a todos los órganos y sistemas del cuerpo, incluyendo el sistema de inmunidad innata y adaptativa (Brock, 2004a).

Araínga et al. (2010) investigaron el fenotipo y genotipo de cepas del VDVB aisladas de bovinos de diversas cuencas leche- ras del Perú encontrando que todas las cepas eran VDVB-1, correspondiendo $85.4 \%$ al tipo no citopático (ncp) y $14.6 \%$ al citopático (cp), sugiriendo la ausencia o baja prevalencia de cepas del VDVB-2. El Servicio de Sanidad Agraria del Perú (SENASA, 2010) reporta una prevalencia predial de DVB de $17.6 \%$, siendo de $2.7 \%$ para Cusco, $44.4 \%$ para Lambayeque y $17.6 \%$ para la región Junín. En bovinos lecheros bajo crianza intensiva en Lima, Aguilar et al. (2006) encontraron $56.0 \%$ de prevalencia, donde 5 de los 12 hatos muestreados no tuvieron animales serorreactores.

Morales (2002) y Jayashi et al. (2005) reportaron $2.8 \%$ de bovinos persistentemente infectados (PI) con DVB, mientras que Huamán et al. (2007) reportó 4.0\% en establos lecheros de crianza intensiva de Arequipa. Así mismo, Huamán et al. (2007) encontraron $47.2 \%$ de seroprevalencia en Majes, Arequipa, mientras que Ståhl (2006) encontró la presencia de anticuerpos contra VDVB en el $95 \%$ de los hatos.

En el caso de Cusco, Álvarez et al. (2002) encontraron $73.7 \%$ de bovinos con anticuerpos contra la DVB en un sistema de crianza mixto comunal, Cárdenas et al. (2011) reportaron $56.2 \%$ en bovinos de Espinar y Cabello et al. (2006) encontraron 90.9\% de bovinos seropositivos en Calca. En Cajamarca se encontró el $27.1 \%$ de animales con anticuerpos contra el VDVB (Herrera 
et al., 2011), mientras que en Melgar, Puno, fue de 48.7\% (Quispe et al., 2008). En el caso del Valle del Mantaro, región Junín, Contreras et al. (2000) encontraron una seroprevalencia de $72.4 \%$, estando positivos todos los hatos muestreados, mientras que Ståhl et al. (2002), en muestras colectadas de tanques de leche encontraron una prevalencia del $73 \%$ para VDVB.

Estudios de prevalencia de la DVB demuestran que esta enfermedad se halla generalizada en la ganadería de la mayoría de los países; sin embargo, existen grandes diferencias en la prevalencia entre diversas áreas geográficas, probablemente como resultado de las diferencias en las prácticas de manejo y de la estructura de los hatos del ganado (Gates et al., 2014). El contacto directo con animales PI es probablemente el método más importante de transmisión de la infección; sin embargo, los estudios de campo han demostrado que algunos brotes de la infección también ocurren en ausencia de los animales PI (Houe, 1995). Es así que para implementar una estrategia de control de la enfermedad en un ámbito geográfico determinado debe tomarse en cuenta estudios epidemiológicos realizados en dicha zona.

Se ha determinado que entre los factores que promueven la difusión viral se encuentran la introducción de reproductores, el movimiento irrestricto del ganado con falta de control de los animales y la existencia de ferias ganaderas donde concurren animales de todo tipo, edad y condición sanitaria (Quispe et al., 2008). El sistema de empadre abierto es, asimismo, un importante factor de riesgo para la introducción de la enfermedad; además, vaquillas preñadas seropositivas llevan el riesgo adicional de la introducción de VDVB a través del nacimiento de terneros PI (Gates et al., 2014).

El objetivo del presente estudio fue determinar la seroprevalencia de DVB y la presencia de animales persistentemente infectados en hatos lecheros del Valle del Mantaro.

\section{Materiales y MéTodos}

El estudio se realizó en establos bovinos lecheros ubicados en las cuatro provincias que conforman el Valle del Mantaro Región Junín, Perú (Huancayo, Chupaca, Concepción y Jauja), tanto en sus márgenes izquierda y derecha, como en las zonas de influencia. El Valle del Mantaro se encuentra a una altitud promedio de $3330 \mathrm{msnm}$. Los propietarios o responsables de los hatos participantes aceptaron los términos establecidos en el documento de consentimiento informado. Para la selección de los animales, se consideró que las vacas estuviesen en ordeño, indistintamente de la raza y edad. En el valle del Mantaro no se realiza vacunación contra diarrea viral bovina.

Para determinar el tamaño muestral para el estudio de la prevalencia de DVD se consideraron las prevalencias reportadas para la región Junín y especialmente en el Valle del Mantaro, empleando la fórmula $\mathrm{n}=\left(\mathrm{z}_{\mathrm{a} / 2}\right)^{2}(\mathrm{pq} /$ $\mathrm{L}^{2}$ ), donde n: tamaño muestral mínimo, Z: nivel de confianza (95\%), $p$ : proporción referencial, $q$ : 1- $p$, y $L$ : error máximo permisible (5\%). La proporción referencial de DVB se obtuvo de los reportes para el Valle del Mantaro del trabajo de Contreras et al. (2000) que indican 72.4\%, de Ståhl et al. (2002) con $96 \%$ y del SENASA (2010) para la región Junín de 17.6\%, y que en promedio representa una proporción referencial del $62 \%$. El tamaño de muestras mínimo fue de 362 , pero para los fines del presente estudio se trabajó con 425 muestras.

Para determinar el número de unidades primarias de muestreo (hatos) por provincia se tomó en cuenta los datos de la población bovina en cada una de las provincias, según datos del CENAGRO (2012), resultando 9 hatos para la provincia de Huancayo, 11 para Concepción, 9 para Jauja y 8 para Chupaca, dando un total de 37 hatos. Para los fines del presente estudio los términos predio y hato se refieren a lo mismo (conjunto de bovinos de un mismo propietario o similar). El prome- 
dio de la población bovina en los hatos en estudio en las cuatro provincias fue $34.5 \mathrm{con}$ un rango de 4-286 (6 hatos con 1-10 bovinos, 16 con $11-30,5$ con $31-60$ y 10 con $>60)$. En cuanto al número de vacas muestreadas por hato y por provincia, en Huancayo el promedio fue 16.1 (rango 6-30), en Chupaca fue 4.1 (rango 2-12), en Concepción fue 11.7 (rango 1-20) y en Jauja fue 13.6 (rango 436). El número de partos por vaca muestreada fue de 2.8 (rango 1-13).

Para el estudio se aplicó un diseño de muestreo de modelo no probabilístico para la selección de los hatos, considerando la accesibilidad del hato, el consentimiento voluntario para la toma de muestras de sus animales y la aplicación de la encuesta epizootiológica. Las muestras de sangre fueron de vacas Holstein, Brown Swiss, cruzadas y criollas de hatos lecheros de crianza intensiva, extensiva y semi-intensiva, sin antecedentes de vacunación contra DVB. Así mismo, para determinar la presencia de animales PI con VDVB se obtuvieron 121 muestras de sangre de bovinos entre 3 y 15 meses de edad (hembras; 117; machos: 4), provenientes de 12 hatos lecheros que presentaron las prevalencias más altas de DVB en las vacas en producción. Los animales muestreados representan la totalidad de animales jóvenes en dichos hatos. Se realizó la prueba de detección de antígeno en las muestras de los animales seronegativos a la detección de anticuerpos.

Las muestras de sangre $(10 \mathrm{ml})$ se obtuvieron por punción de la arteria coccígea media, utilizando tubos vacutainers estériles sin anticoagulante. Las muestras fueron procesadas en el Laboratorio de Sanidad Animal de la Facultad de Zootecnia de la Universidad Nacional del Centro del Perú (UNCP) en Huancayo, y conservadas en congelación a $-20^{\circ} \mathrm{C}$. El análisis de las muestras se realizó en el Laboratorio de Biología y Genética Molecular de la Facultad de Medicina Veterinaria de la Universidad Nacional Mayor de San Marcos (Lima) y en el laboratorio antes indicado de la UNCP.
Para la detección de anticuerpos contra VDVB en muestras de suero se utilizó un kit comercial contra la proteína p 80 del BVDV mediante ELISA de bloqueo (CIVTEST Bovis BVD/BD P80, Lab. Hipra) y un kit para detección de anticuerpos frente a VDVB (IDEXX BVDV Total Ab Test, Lab. Multivet). Así mismo, para la detección de antígeno del VDVB en muestras de suero se trabajó con un kit contra la glucoproteína $\mathrm{E}^{\mathrm{rns}}$ del VDVB (IDEXX BVDV PI X2 Test, Lab. Multivet). Las lecturas se hicieron en lectoras de placas ELISA (BioRad 680 con filtro $450 \mathrm{~nm}$ y Biotek Modelo ELx800 con filtro $450 \mathrm{~nm})$.

Para la caracterización de los sistemas de producción se tomaron como criterios el tipo de estabulación y equipamiento, tipo de ordeño (mecánico o manual), uso de inseminación artificial o monta natural, uso de suplementos alimenticios y concentrado, tipo de instalaciones, uso de registros, tipo de personal y sistema de manejo, lo cual permitió categorizar a los sistemas como intensivo, semiintensivo y extensivo. Se consideró que el hato lechero es cerrado cuando no suele adquirir animales de otros establecimientos y abierto cuando adquiere con frecuencia animales de otras procedencias; el origen de los reemplazos en el hato es propio cuando las vaquillas son hijas de las vacas del hato (hatos cerrados) y no propio cuando estos animales se adquieren de otros hatos (hatos abiertos). Las vacas repetidoras son aquellas que necesitan de más de tres servicios para concebir. Las causas de saca se categorizaron por criterios de edad, problemas reproductivos, productivos o varias simultáneamente. Los nacimientos anómalos se refieren a la presencia de malformaciones congénitas en los neonatos y problemas de partos distócicos (Arauco, 2015).

La prevalencia (\%) de DVB se calculó mediante la fórmula ( $\mathrm{N}^{\circ}$ muestras positivas/ total de muestras) * 100. La prevalencia por hato para cada provincia se determinó promediando la prevalencia de cada uno de los hatos sobre el número de hatos evaluados 
en la provincia. Los niveles de prevalencia fueron considerados como Bajo $(<26 \%)$, Moderado Bajo (e» $26-<51 \%$, Moderado Alto (e»51-<76\%) y Alto (e»76) (Arauco, 2015).

Para el análisis de los datos se utilizó el paquete estadístico SPSS v. 21. Se determinó la prevalencia con sus respectivos intervalos de confianza, se hizo la correlación de Spearman y el análisis de regresión logística binaria, así como tablas de contingencia con Chi cuadrado y medidas de asociación (riesgo) como Odds Ratio (OR). Además, se utilizó una encuesta epizootiológica que fue validada en su contenido por un panel de expertos. Los resultados de la evaluación diagnóstica para DVB (seropositivos o seronegativos) y los de la encuesta epidemiológica fueron analizados con el programa Stata v. 13.0 (Stata Corp ${ }^{\circledR}$ ). Se hizo un análisis de regresión logística multinomial de efectos mixtos RLMEM (Multilevel mixed-effects logistic regression), determinándose como parámetros de efectos aleatorios a la variable «Hato de procedencia», mientras que como parámetros de efectos fijos fueron consideradas las demás variables obtenidas en la encuesta.

La encuesta fue aplicada a los responsables de los predios y se complementó, en algunos casos, con la revisión de registros existentes en los predios, identificando y ca- racterizando los factores de riesgo que pueden asociarse con la presentación de DVB.

Se explicó al propietario o responsable del predio el alcance del estudio y el destino de las muestras, recalcando el compromiso de hacerles llegar, de manera confidencial, los resultados de las pruebas diagnósticas de sus animales, para lo cual firmaron un documento de conformidad, en concordancia con las consideraciones bioéticas establecidas en el proyecto de investigación.

\section{Resultados y Discusión}

\section{Prevalencia de DVB}

La prevalencia muestral para DVB, considerando las cuatro provincias del Valle del Mantaro, fue $64.8 \%$ y la prevalencia por hato de $66.3 \%$. La provincia de Concepción registró la prevalencia muestral y por hato más altas (75.2 y 75.5\%, respectivamente), siendo menor en la provincia de Huancayo (48.3 y 52.3\%, respectivamente) (Cuatro 1). Estos valores coinciden con el trabajo de Contreras et al. (2000) quienes indican una mayor prevalencia para Concepción $(86.3 \%)$ y menor para Huancayo (41.3\%), detectando el VDVB en todos los hatos muestreados en un rango de 9.4 a $100 \%$.

Cuadro 1. Prevalencia muestral y por hato de diarrea viral bovina (DVB) en el Valle del Mantaro, Junín

\begin{tabular}{lccccc}
\hline Provincia & $\begin{array}{c}\text { Muestras } \\
(\mathrm{n})\end{array}$ & Hatos (n) & $\begin{array}{c}\text { Prevalencia } \\
\text { muestral }(\%)\end{array}$ & $\begin{array}{c}\text { Prevalencia } \\
\text { por hato } \\
(\% \pm \mathrm{DE})\end{array}$ & $\begin{array}{c}\text { IC por hato } \\
(95 \%)\end{array}$ \\
\hline Huancayo & 145 & 9 & 48.3 & $52.3 \pm 25.9$ & \pm 19.9 \\
Chupaca & 33 & 8 & 69.7 & $62.5 \pm 32.7$ & \pm 27.4 \\
Concepción & 125 & 11 & 75.2 & $75.5 \pm 21.6$ & \pm 14.5 \\
Jauja & 122 & 9 & 72.1 & $66.2 \pm 25.4$ & \pm 19.6 \\
\hline Total & 425 & 37 & 66.3 & $64.8 \pm 26.6$ & \pm 8.9 \\
\hline
\end{tabular}


Cuadro 1. Prevalencia muestral y por hato de diarrea viral bovina (DVB) en el Valle del Mantaro, Junín

\begin{tabular}{lccccc}
\hline Provincia & $\begin{array}{c}\text { Muestras } \\
(\mathrm{n})\end{array}$ & Hatos (n) & $\begin{array}{c}\text { Prevalencia } \\
\text { muestral }(\%)\end{array}$ & $\begin{array}{c}\text { Prevalencia } \\
\text { por hato } \\
(\% \pm \mathrm{DE})\end{array}$ & $\begin{array}{c}\text { IC por hato } \\
(95 \%)\end{array}$ \\
\hline Huancayo & 145 & 9 & 48.3 & $52.3 \pm 25.9$ & \pm 19.9 \\
Chupaca & 33 & 8 & 69.7 & $62.5 \pm 32.7$ & \pm 27.4 \\
Concepción & 125 & 11 & 75.2 & $75.5 \pm 21.6$ & \pm 14.5 \\
Jauja & 122 & 9 & 72.1 & $66.2 \pm 25.4$ & \pm 19.6 \\
\hline Total & 425 & 37 & 66.3 & $64.8 \pm 26.6$ & \pm 8.9 \\
\hline
\end{tabular}

Cuadro 2. Riesgo de seropositividad a diarrea viral bovina (DVB) en cuatro provincias del Valle del Mantaro, Perú

\begin{tabular}{lccc}
\hline Provincia & Odds ratio & p-value & IC 95\% \\
\hline Huancayo (ref) & & & \\
Chupaca & 2.51 & 0.157 & $0.700-9.018$ \\
Concepción & 3.47 & $0.011^{*}$ & $1.327-9.087$ \\
Jauja & 3.06 & $0.030^{*}$ & $1.112-8.412$ \\
\hline
\end{tabular}

* Indica un valor de OR estadísticamente diferente de $1(p<0.05)$

La mayoría de los reportes de prevalencia de DVB a nivel mundial indican valores entre 60 y $80 \%$ de bovinos seropositivos (Kobrak y Wever, 1997). En el Perú, el SENASA (2010) reportó una prevalencia predial de DVB de $17.6 \%$, con prevalencias variables según las regiones. Así mismo, diversos autores reportaron prevalencias de DVB con valores entre 49 y $95 \%$, dependiendo, igualmente, de las regiones del país y del tipo de ganado muestreado (Álvarez et al., 2002; Aguilar et al., 2006; Cabello et al., 2006; Ståhl, 2006; Huamán et al., 2007; Quispe et al., 2008; Cárdenas et al., 2011). No se encontró diferencia significativa entre las medias de los valores de prevalencia de DVB (muestral y por hato) entre las provincias. Sin embargo, al realizar el análisis RLMEM se demostró un efecto significativo
Cuadro 3. Niveles de presencia de diarrea viral bovina (DVB) en hatos bovinos del Valle del Mantaro, Junín, Perú

\begin{tabular}{lcc}
\hline \multirow{2}{*}{ Nivel } & \multicolumn{2}{c}{ Hatos } \\
\cline { 2 - 3 } & $\mathrm{n}$ & $\%$ \\
\hline Bajo & 3 & 8.1 \\
Moderado Bajo & 11 & 29.7 \\
Moderado Alto & 9 & 24.4 \\
Alto & 14 & 37.8 \\
\hline Total & 37 & 100.0 \\
\hline
\end{tabular}

de la procedencia de los animales sobre la seropositividad a DVB, observándose un incremento en el riesgo de seropositividad de 3.5 veces en vacas procedentes de Concepción en comparación a las vacas de Huancayo (Referencial; $\mathrm{p}=0.01$ ), mientras que el riesgo 
Cuadro 4. Factores de riesgo para la presentación de diarrea viral bovina (DVB) en ganado bovino en cuatro provincias del Valle del Mantaro, Junín, Perú

\begin{tabular}{lc}
\hline Variable & Odds ratio (OR) \\
\hline Tipo de servicio (IA/Monta natural - Monta natural) & 7.9 \\
Sistema de producción (intensivo - no intensivo) & 6.5 \\
Tipo de hato (abierto - cerrado) & 6.3 \\
Presencia de ratas (masiva y constante) & 5.7 \\
Origen de los reemplazos (propios - externos) & 0.2 \\
\hline
\end{tabular}

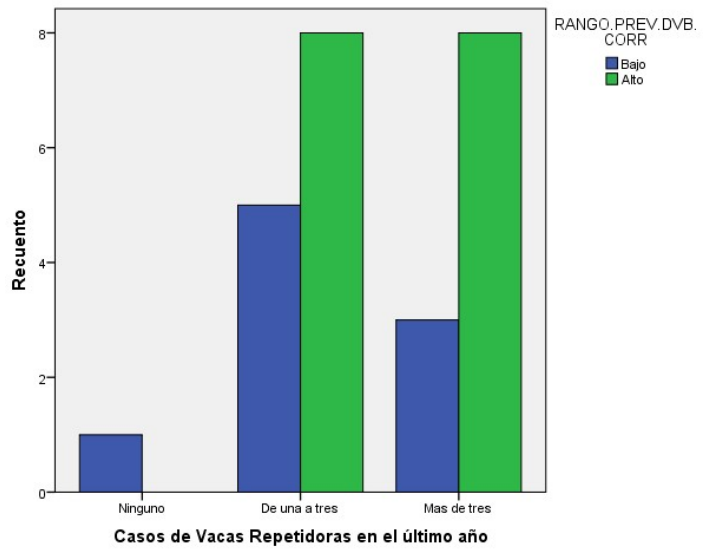

Figura 1. Frecuencia de vacas repetidoras por hato y su relación con el nivel de prevalencia de diarrea viral bovina

de seropositividad a DVB fue 3.06 veces mayor en vacas procedentes de Jauja que en vacas de Huancayo (Referencial; $p=0.03$ ) (Cuadro 2).

\section{Prevalencia de DVB por Hato}

El $62.2 \%$ de los hatos presentó niveles de prevalencia de DVB entre alto y moderado alto (prevalencias entre 51 y 100\%), mientras que $8.1 \%$ de los hatos presentó niveles bajos (prevalencias entre 0 y 26\%) (Cuadro 3). La provincia de Concepción registró el mayor número de hatos con niveles de prevalencia alto de DVB (entre 76 y 100\%), indicativo una importante presencia de DVB.

\section{Tipo de Servicio}

Al contrastar el tipo de servicio (monta natural $[\mathrm{MN}]$ vs. inseminación artificial [IA] más $\mathrm{MN}$ ) con el nivel de prevalencia de DVB (alto o bajo) en los hatos (Cuadro 4), se encuentra que esta variable constituye un factor de riesgo (OR: 7.895). Los hatos donde se practica la IA de manera exclusiva u ocasional están más propensos a infectarse con DVB. El semen de toros PI o con infección aguda de DVB es una importante vía de transmisión horizontal del virus, ya que los espermatozoides pueden sobrevivir los procesos de criopreservación y procesamiento del semen para la IA y, por lo tanto, se puede infectar a las hembras con el semen (Kirkland et al., 1997).

\section{Sistema de Producción}

El valor de OR para la variable sistema de producción (intensivo y no intensivo) con relación al porcentaje de prevalencia/hato de DVB (nivel alto y nivel bajo) fue de 6.5, por lo que el riesgo de presentar altas prevalencias de DVB es 6.5 veces superior en los hatos con sistema de producción intensivo que en los hatos con sistema de producción semiintensivo y extensivo (Cuadro 4). Esto se explicaría porque la tendencia hacia los sistemas estabulados con el objeto de buscar altas producciones individuales ocasiona en ciertos casos, un mayor estrés en las vacas que las predisponen a diversas enfermeda- 
des ante un sistema inmunológico deprimido (Glauber, 2013). Además la diseminación de la DVB se vería favorecida por la posibilidad de un mayor contacto entre animales. Por otro lado, si el VDVB ingresa a un hato de crianza extensiva o semi extensiva, es de esperarse que se infecte la mayoría de los animales; sin embargo, las manifestaciones clínicas (abortos, nacimiento de terneros PI, etc.) no se aprecian de manera marcada y los animales seroconvierten quedando protegidos contra futuras reinfecciones, siendo la infección autolimitante en este tipo de manejo (Ståhl et al., 2008).

\section{Presencia de Ratas}

La presencia masiva y constante de roedores en el hato constituye un factor de riesgo para la presencia de altas prevalencias de DVB (OR: 5.714; Cuadro 4). Todos los establos evaluados declararon la presencia de ratas en sus instalaciones (ya sea de manera ocasional o esporádica, o de manera permanente y masiva). Como el virus está presente en el moco nasal, en saliva, orina, excremento y otras excreciones, así como en utensilios o herramientas que estuvieron en contacto con animales enfermos, la presencia masiva de estos roedores puede convertirse en una importante fuente de diseminación del virus en el hato (Córdova, 2010).

\section{Tipo de Hato y Origen de los Reemplazos}

Considerando a los hatos como «cerrados» $\mathrm{y}$ 《abiertos» se encontró un valor de OR 6.3 con un $\mathrm{IC}_{95 \%}$ que se sitúa entre 1.398 y 28.698 , por lo que el riesgo de presentar altas prevalencias de DVB es 6.33 veces superior en los hatos abiertos que en los hatos cerrados (Cuadro 4). En lo referente al origen de los reemplazos (propios o externos al hato) se encontró un OR 0.12 , lo que indica que es un factor de protección para la no presentación de prevalencias altas de DVB, que los hatos obtengan los reemplazos de su propio hato.
Bajo las condiciones de los sistemas productivos en el Valle del Mantaro, se ha considerado como hato cerrado a los establecimientos donde los reemplazos provienen exclusivamente del mismo, obviando el hecho de que se intercambian o venden o presten reproductores entre hatos vecinos, y que participan en ferias de exposición o venta de ganado. El 45.9\% declaró, bajo estas circunstancias, ser de tipo abierto, $32.4 \%$ puede considerarse de tipo cerrado y un $21.7 \%$ semi abierto. Estos últimos adquieren sus animales (no necesariamente como reemplazos de las vacas) de manera ocasional de otros establecimientos.

Diversos estudios coinciden en que el mantenimiento de empadres abiertos es el principal factor de riesgo para la introducción de la enfermedad y que la adquisición de ganado puede generar un aumento del riesgo de generar brotes en el hato de destino (Houe, 1993). Así mismo. Kadohira y Tajima (2009) indican que la reciente compra de ganado y la falta de medidas de prevención para el ingreso de personas y animales en las instalaciones son factores que aumentan significativamente el riesgo de producir ganado PI. En Melgar, Puno, se ha reportado que la introducción de reproductores y el movimiento irrestricto del ganado con falta de control y las ferias ganaderas constituyen potenciales fuentes de contagio (Quispe et al., 2008). Un componente epidemiológicamente importante de este factor es la «intermediación» en la compraventa de animales (Gates et al., 2014), de allí la necesidad de incluir medidas de bioseguridad para evitar la introducción de animales infectados en el rebaño y cuarentena de los animales sospechosos para controlar la diseminación del virus (Brock, 2004b).

\section{Vacas Repetidoras}

La ocurrencia de vacas repetidoras en un hato es por lo general de tipo multicausal, pero la presencia de enfermedades reproductivas como la DVB suele reflejarse 
con este cuadro clínico (Palomares-Naveda, 2008). En el análisis de factores de riesgo no se pudo definir plenamente que la presencia de vacas repetidoras en un hato constituya un factor de riesgo para la presentación de DVB; sin embargo, se encontró un importante nivel de asociación entre la presencia de vacas repetidoras en el hato durante el último año $(0,1-2$, $>3$ casos) en los 25 hatos donde se dispuso de esta información con la presentación de niveles de prevalencia alta de DVB. En general, hatos sin presencia de vacas repetidoras no presentaron niveles altos de prevalencia de DVB, y en aquellos con al menos una vaca repetidora tuvieron todos los casos de altas prevalencias (prevalencia alta y moderadamente alta) de DVB (Figura 1).

\section{Causas de Saca}

$\mathrm{Al}$ asociar los porcentajes de prevalencia de DVB por hato con relación a las principales causales de saca de las vacas en el establo, los problemas reproductivos y la edad constituyeron la principal causa de saca en los hatos con mayor prevalencia de DVB, mientras que la baja producción fue la principal causa de saca en hatos con baja prevalencia de DVB.

\section{Abortos y Anomalías al Nacimiento}

Se asoció la aparición de abortos, nacimientos anómalos (natimortos y terneros débiles) y terneros que nacen con malformaciones congénitas, reportados en los últimos tres años, con los porcentajes de prevalencia/hato para DVB. Los resultados indicaron que el $66.7 \%$ de hatos con prevalencias más altas tuvieron todos los casos de nacimientos anómalos, el $50 \%$ de hatos con valores de prevalencias moderadas solo reportaron nacimientos de terneros con malformaciones congénitas, y hatos con prevalencias bajas no reportaron nacimientos anómalos. Estos resultados son coherentes con otros reportes, ya que la infección con el VDVB puede causar diversas manifestaciones clínicas (Baker, 1995).

\section{Animales PI}

Se colectaron 51 muestras en Jauja, 41 en Huancayo, 20 en Concepción y 9 en Chupaca, haciendo un total de 121 muestras. La prevalencia de animales persistentemente infectados (PI) con DVB fue de 5.8\%. El número de animales PI fue de 4, 4, 1 y 0 para Huancayo, Concepción, Jauja y Chupaca, respectivamente. En el caso de Huancayo, dos hatos tuvieron dos animales PI cada uno y en el caso de Concepción un hato tuvo dos animales PI. El hato de Jauja y el hato de Concepción registraron un nivel de prevalencia/hato de DVB Alto, mientras que los dos hatos de Huancayo presentaron niveles de prevalencia/hato moderado bajo y moderado alto.

Reinhardt et al (2003) en un estudio en nueve planteles lecheros en Chile, reportó una prevalencia promedio de animales PI de $0.3 \%$, variando entre los predios positivos entre 0.7 y $1 \%$. Estudios en el país señalan prevalencias de terneros PI en Arequipa de $0.76 \%$ (Morales, 2002) y de 2.7 y 4.0 en establos lecheros de Arequipa (Jayashi et al., 2005 y Huamán et al., 2007, respectivamente).

Los animales PI pueden presentar diarrea intermitente, neumonía, elevada incidencia de infecciones varias, retraso en el crecimiento (Baker, 1995; Voges et al., 1998), etc., por lo que se asume un malfuncionamiento del sistema inmunitario; sin embargo, la existencia de algunos PI normales, que incluso llegan a reproducirse, demuestra la inocuidad de algunas de estas infecciones en estos animales. Lo que sí hacen todos los animales PI, independientemente de su origen, es eliminar virus al ambiente en altas cantidades y constituyen la principal fuente de infección de DVB (Matsuno et al., 2007). Por esta razón, cualquier plan de control del VDVB, 
ya sea a nivel regional o de hato, debe incluir la eliminación de todos los animales PI.

\section{Conclusiones}

- La prevalencia muestral de diarrea viral bovina (DVB) para el Valle del Mantaro fue $64.7 \%$ y la prevalencia/hato de $64.8 \%$.

- La prevalencia de animales persistentemente infectados (PI) con DVB fue $5.8 \%$.

- Los factores de riesgo para la presentación de DVB fueron el sistema intensivo de producción (OR: 6.545), hatos de tipo abierto (OR: 6.33), uso de inseminación artificial (OR: 7.895) y la presencia de ratas (OR: 5.714).

- Hay asociación positiva entre altas prevalencias de DVB con la presencia de vacas repetidoras y de casos de abortos y nacimientos anómalos en el hato.

\section{Literatura Cittada}

1. Aguilar R, Benito A, Rivera H. 2006. Seroprevalencia del virus de la diarrea viral bovina en ganado lechero de crianza intensiva del valle de Lima. Rev Inv Vet Perú 17: 148-153. doi: 10.15381/ rivep.v17i2.1530

2. Álvarez L, Rivera H, Pezo D, García $W .2002$. Detección de anticuerpos contra pestivirus en rumiantes de una comunidad campesina de la provincia de Canchis, Cusco. Rev Inv Vet Perú 13: 46-51. doi: 10.15381/rivep.v13i1.1705

3. Araínga M, Rivera H, Huamán JC, Manchego A. 2010. Fenotipo y genotipo del virus de la diarrea viral aislado de bovinos en el Perú. Rev Inv Vet Peru 21: 192-203. doi: 10.15381/rivep.v21i2.137

4. Arauco VF. 2015. Epidemiología y caracterización de los factores de riesgo- de diarrea viral bovina y neosporosis en bovinos del Valle del Mantaro - región Junín. Tesis Doctoral. Lima, Univ. Nacional Mayor de San Marcos. 179 p.

5. Baker JC. 1995. The clinical manifestations of bovine viral diarrhea infection. Vet Clin N Am-Food A 11: 425-445. doi: 10.1016/S0749-0720(15)30460-6

6. Brock $K V$. 2004a. The many faces of bovine viral diarrhea virus. Vet Clin $\mathrm{N}$ Am-Food A 20: 1-3. doi: 10.1016/ j.cvfa.2003.12.002

7. Brock KV. 2004b. Strategies for the control and the prevention of bovine viral diarrhea virus. Vet Clin N Am-Food A 20: 171-180. doi: 10.1016/j.cvfa.2003.12.003

8. Cabello K, Quispe R, Rivera H. 2006. Frecuencia de los virus Parainfluenza 3, Respiratorio sincitial y diarrea viral bovina en un rebaño mixto de una comunidad campesina de Cusco. Rev Inv Vet Perú 17: 167-172. doi: 10.15381/ rivep.v17i2.1535

9. Cárdenas $C$, Rivera $H$, Arainga $M$, Ramírez M, De Paz J. 2011. Prevalencia del virus de la diarrea viral bovina $\mathrm{y}$ de animales portadores del virus en bovinos de la provincia de Espinar, Cusco. Rev Inv Vet Perú 22: 261-267. doi: 10.15381/rivep.v22i3.268

10. [CENAGRO-JUNIN] Censo Nacional Agropecuario, Junín. 2012. Resultados definitivos del IV Censo Nacional Agropecuario. [Internet]. Disponible en: http://censos.inei.gob.pe/cenagro/tabulados/

11. Contreras G, Ståhl K, Arana C. Rivera H. 2000. Anticuerpos contra el virus de la diarrea viral bovina en muestras de leche de bovinos del Valle del Mantaro (Jauja, Concepción y Huancayo). Rev Inv Vet del Perú 11: 58-65. doi: 10.15381/ rivep.v11i1.6798

12. Córdova DL. 2010. Enfermedades que provocan aborto en bovinos en San Luis de Potosí. INIFAP. Folleto Técnico. Coyoacán, México DF. 54 p. 
13. Gates MC, Humphry RW, Gunn GJ, Woolhouse ME. 2014. Not all cows are epidemiologically equal: quantifying the risks of bovine viral diarrhoea virus (BVDV) transmission through cattle movements. Vet Res 45: 110. doi: 10.1186/s13567-014-0110-y

14. Glauber C. 2013. Sanidad e intensificación en el tambo: el riesgo de la diarrea viral bovina (DVB). Rev Vet Argentina 30: 1-5.

15. Grooms DL. 2004. Reproductive consequences of infection with bovine viral diarrhea virus. Vet Clin Food Anim Pract 20: 5-19. doi: 10.1016/ j.cvfa.2003.11.006

16. Herrera A, Manchego A, Ramírez M, More BJ, Rivera $H .2011$. Seroprevalencia del virus de la diarrea viral en bovinos de crianza extensiva de la provincia de San Pablo, Cajamarca. Rev Inv Vet Perú 22: 171-175. doi: 10.15381/rivep.v22i2.294

17. Houe H. 1993. Survivorship of animals persistently infected with bovine virus diarrhoea virus (BVDV). Prev Vet Med 15: 275-283. doi: 10.1016/01675877(93)90099-F

18. Ноие Н. 1995. Epidemiology of bovine viral diarrhea virus. Vet Clin NAm-Food A 11: 521-547. doi: 10.1016/S07490720(15)30465-5

19. Huamán J, Rivera H, Araínga M, Gavidia C, Manchego A. 2007. Diarrea viral bovina y animales portadores del virus en hatos productores de leche de la Irrigación de Majes, Arequipa. Rev Inv Vet Perú 18: 141-149. doi: 10.15381/ rivep.v18i2.1290.

20. Jayashi C, Gavidia C, Araínga M, Manchego A, Rivera H. 2005. Dinámica de seroconversión en hembras bovinas post eliminación de animales portadores del virus de la diarrea viral bovina. Rev Inv Vet Perú 16: 56-64. doi: 10.15381/rivep.v16i1.1536

21. Kadohira M, Tajima M. 2009. Case control study of BVDV persistent- infection (PI) in Betsukai, Hokkaido, Japan. J Vet Med Sci 72: 635-638. doi: 10.1292/jvms.09-0305

22. Kirkland PD, McGowan MR, Mackintosh SG, Moyle A. 1997. Insemination of cattle with semen from a bull transiently infected with pestivirus. Vet Rec 140: 124-127. doi: 10.1136/ vr.140.5.124

23. Kobrak A, Wever EL. 1997. Bovine diarrhea virus: an update. Rev Argent Microbiol 29: 47-61.

24. Matsuno K, Sakoda Y, Kameyama K, Tamai K, Ito A, Kida H. 2007. Genetic and pathobiological characterization of bovine viral diarrhea viruses recently isolated from cattle in Japan. J Vet Med Sci 69: 515-520. doi: 10.1292/jvms.69.515

25. Morales CS. 2002. Detección de terneros con infección congénita con el virus de la diarrea viral bovina en dos hatos lecheros de la provincia de Arequipa. Tesis de Médico Veterinario. Lima, Perú: Univ. Nacional Mayor de San Marcos. 45 p.

26. Palomares-Naveda R.A. 2008. Desarrollo sostenible de ganadería doble propósito: diagnóstico de la diarrea viral bovina para la mejora de la eficiencia reproductiva. En: González-Stagnaro C, Soto E (eds). Manual de ganadería doble propósito. [Internet]. Disponible en: h t t p : / / w w w a v pa.ula.ve/ libro_desarrollosost/pdf/capitulo_53.pdf

27. Paton DJ. 1995. Pestivirus diversity. J Comp Pathol 112: 215-236. doi: 10.1016/ S0021-9975(05)80076-3

28. Quispe R, Ccama A, Rivera H, Araínga M. 2008. El virus de la diarrea viral en bovinos criollos de la provincia de Melgar, Puno. Rev Inv Vet Perú 19: 176182. doi: 10.15381/rivep.v19i2.1165

29. Reinhardt G, Ochoa CA, Tadich N, Riedemann S. 2003. Utilización del método de ELISA en la detección directa de antígeno de virus diarrea viral bovina en muestras de suero sanguíneo de bovinos. Arch Med Vet 35: 89-93. doi: 10.4067/S0301-732X2003000100009 
30. [SENASA] Servicio de Sanidad Agraria. 2010. Caracterización de la diarrea viral bovina, neosporosis bovina $\mathrm{y}$ rinotraqueitis infecciosa bovina en el Perú. [Internet]. Disponible en: https://www.senasa.gob.pe/senasa/descar-gasarchivos/ jer/BOVINOS/Caracte-rizacion\%20DVB $\% 20 \mathrm{NB} \% 20 \mathrm{y} \%$-20RIB.pdf

31. Ståhl K, Rivera H, Vågsholm I, Moreno-López J. 2002. Bulk milk testing for antibody seroprevalences to BVDV and BHV-1 in a rural region of Peru. Prev Vet Med 5: 193-202. doi: 10.1016/ S0167-5877(02)00161-7

32. Ståhl K. 2006. Bovine viral diarrhoea virus and other reproductive pathogens. Epidemiological studies in Peruvian cattle. PhD Thesis. Uppsala, Sweden: Swedish University of Agricultural Sciences. $44 \mathrm{p}$.

33. Ståhl K, Lindberg A, Rivera H, Ortiz C, Moreno-López J. 2008. Selfclearance from BVDV infections - a frequent finding in dairy herds in an endemically infected region in Peru. Prev Vet Med 83: 285-296. doi: 10.1016/ j.prevetmed.2007.08.005

34. Valle PS, Skjerve E, Martin SW, Larssen RB, Osterås $O$, Nyberg $O$. 2005. Ten years of BVDV control in Norway: a cost benefits analysis. Prev Vet Med 72: 189-207. doi: 10.1016/ j.prevetmed.2005.07.017

35. Vega S, Rosell R, Paton DJ, Orden JA, de la Fuente R. 2000. Antigenic characterization of BVDV isolates from Spain with of monoclonal antibodies. $\mathrm{J}$ Vet Med B 47: 701-706.

36. Voges H, Horner GW, Rowe S, Wellenberg GJ. 1998. Persistent bovine pestivirus infection localized in the testes of an immuno-competent, nonviraemic bull. Vet Microbiol 61: 165-175. doi: 10.1016/S0378-1135(98)00177-1 